\title{
Efficacy of Dialectical Behavior Therapy on Stress, Resilience and Coping Strategies in Irritable Bowel Syndrome Patients
}

\author{
Sayed Abbas Haghayegh, ${ }^{1,}{ }^{*}$ Hamid Taher Neshatdoost, ${ }^{2}$ Peiman Adibi, ${ }^{3}$ and Farah Shafii ${ }^{4}$ \\ ${ }^{1}$ Department of Psychology, Faculty of Humanities, Najafabad Branch, Islamic Azad University, Najafabad, Iran \\ ${ }^{2}$ Department of Psychology, Faculty of Psychology and Education, University of Isfahan, Isfahan, Iran \\ ${ }^{3}$ Department of Gastroenterology and Liver Disease, Faculty of Medicine, Isfahan University of Medical Sciences, Isfahan, Iran \\ ${ }^{4}$ Department of Psychology, Isfahan University of Medical Sciences, Isfahan, Iran \\ "Corresponding author: Sayed Abbas Haghayegh, Department of Psychology, Faculty of Humanities, Najafabad Branch, Islamic Azad University, Najafabad, Isfahan, Iran. \\ E-mail: abbas_haghayegh@yahoo.com
}

Received 2016 February 27; Revised 2016 July 03; Accepted 2017 January 09.

\begin{abstract}
Background: Irritable bowel syndrome (IBS) is the most common gastrointestinal disorder that have considerable psychological features.

Objectives: This research aimed to determine the efficacy of dialectical behavioral therapy on stress, resilience and coping strategies of IBS patients.

Methods: The study was quasi-experimental that including two intervention and control groups. Fifty-two IBS patients who met this diagnosis- according the Rome III criteria- were selected and assigned to two experimental and control groups with 26 IBS patients in each group. The dialectical behavioral therapy-according to Moonshine s manual- was conducted in 8 weekly sessions in a gastroenterology clinic in Isfahan. The questionnaires of stress, resilience and coping strategies were completed as the pretest, post-test and follow-up. Data were analyzed with SPSS.20.

Results: Results of multivariate analysis of variance showed that dialectical behavioral therapy had a significant effect in reduction of post-test mean scores of emotional coping strategies $(\mathrm{P}<0.05)$, and there was an acceptable effect size for all variables (except avoidance strategies).

Conclusions: Dialectical behavioral therapy could be useful to improvement of psychological status of IBS patients, but it needs longer therapeutic period for more persistent effects.
\end{abstract}

Keywords: Irritable Bowel Syndrome, Coping Strategies, Dialectical Behavioral Therapy, Stress, Resilience

\section{Background}

Irritable bowel syndrome (IBS) is the most common functional gastrointestinal disorder $[1,2]$. The worldwide prevalence of IBS in adults is between 9.0\% and 23.5\% [3]. Understanding and perception of pathology and treatment of irritable bowel syndrome have changed from a bio-medical reductionistic approach to a psycho-sociobiological complex syndrome during three past decades $[4,5]$. IBS has significant psychological components and its high association with mental disorders has been confirmed [6] and high correlation between severity of symptoms of IBS and psychological factors has been reported [7].

Stress is one of most important factors in expression of physical illnesses and psychological disorders [8]. According to the results of some researches, psychological stressors and traumatic factors have important role in generation symptoms of IBS [9].

Resilience and coping strategies are two factors that are directly related to outcomes of stress and could be a mediating factor of stress. Resilience has been defined to tolerance stress and regression to psychological balance [10]. Several researches showed that people with higher of Resilience, have more self-regulation skills, higher selfesteem, lower rate of physical illnesses and psychological disorders and duration of adjustment in confrontation to environmental stressors [11].

Coping strategies are defined to cognitive and behavioral attempts to management of daily stressors and satisfaction of needs. These strategies include: Problemoriented strategies, Emotion-oriented strategies and Aversion-oriented strategies [12]. In most of stressful situations, problem-oriented strategies and more adjusted and effective than emotion- oriented strategies. Patients with IBS, have not effective methods to manage their stressors. It especially is in considering to training of methods of stress management have positive results in degree of bowel symptoms of these patients [13]. The poor coping strategies has been significant relation with quality of life in patients with IBS [14].

In IBS, as a chronic disease, various dimensions of life such as job activities, traveling, interpersonal relation- 
ships and enjoyment are disrupted [15]. Numerous of researchers agree with importance and necessity of psychological therapies in IBS [16].

Dialectical behavior therapy (DBT) is a modern, structured, and goal-oriented therapeutic method whose efficacy has been proved successful on a number of psychological disorders such as borderline personality disorders, eating disorders [17], abuse substance [18], adolescents with ADHD [19], depression [20], and pervasive development disorders [21]. Currently, DBT has been used in physiologicalpsychological illnesses and shown hopeful results [22]. This treatment consists of four components: mindfulness, distress tolerance, emotion regulation, and interpersonal effectiveness [23, 24].

There are various common similarities between the health structure of this approach and the nature of psychological problems of irritable bowel syndrome. DBT firstly designed for borderline personality disorder (BPD). Early abuse and emotional problems are common in BPD [25]. Most of IBS patients have negative emotional experiences in early life [26] and currently [27] that influence in their emotional and bowel symptoms. IBS patients have high level of distress and poor coping strategies [14] and need to learn skills to control it. DBT has effective and clear behavioral techniques [17] could be effective to manage their negative emotions. Currently, DBT has been used in physiological-psychological illnesses and shown hopeful results [22].

\section{Objectives}

So, the purpose of current research was to study the efficacy of DBT on stress, resilience, and coping strategies of patients with diagnosis of irritable bowel syndrome.

\section{Methods}

The study was quasi-experimental that including patients in two intervention and control groups. Three measurements were done: pretest, post-test, and at two months follow-up. The study population included patients with DBT (diagnosed by specialists and based on the criteria of Rome III), who referred to Al-Zahra hospital. Fifty two IBS patients were selected and assigned to two experiment (26 cases) and control (26 cases) groups. The criteria below were considered in selection of patients.

\subsection{Inclusion Criteria}

1) Patients should not have participated in other psychological interventions concurrently; 2) Participants had not reported diagnosis of non-functional gastrointestinal illnesses. 3) Women patients had not been in pregnancy; 4) Participants had not meet diagnosis of schizophrenia and bipolar disorders.

\subsection{Exclusion Criteria}

Three or more absences in the group sessions.

Covariate variables: 1) demographical variables (age, birth order, and education); 2) clinical variables (global psychological status, mind-body attribution, and duration of disease). Intervention design

\subsection{Experimental Group}

DBT was conducted in eight sessions (without pretest and posttest) according to Mooshine manual [28] in a clinic for gastrointestinal patients. According to Mooshine manual, DBT consists of mindfulness (sessions 1 and 5), emotion regulation (sessions 2 and 6), distress tolerance (sessions 3and 7), and interpersonal effectiveness (sessions 4 and 8). Regarding mindfulness, it was attempted to expose patients to their current life problems, thoughts, and feelings that avoided them, awareness of which would help them solve the so-called problems in next stages. With respect to emotion regulation, problems and negative feelings were selected, and behavioral techniques were trained to reduce these problems, only behavioral techniques, not cognitive or any other technique. In distress tolerance, problems and feelings that could not be solved were selected and it was attempted to increase the tolerance and maintain the motivation and hardiness of the patients. In interpersonal effectiveness, it was focused on supportive network and social self-esteem of patients. Five members in the posttest stage and one in the follow-up were removed.

\subsection{Control Group}

Psycho-educational control group interactions are indicated as effective in therapeutic outcomes. Psychoeducational group treatment was conducted in four sessions (without pretest and posttest). They were familiar with etiology and the role of psychological factors in IBS, without any psychotherapy. Eight members were removed in the posttest phase.

\subsection{Instruments}

Depression-anxiety-stress scale (DASS): DASS was published by Lovibond and Lovibond in 1995. Short form of DASS conclude 21 sentences that each 7 sentences in related to one subscale. In this research, has been used of subscale of stress. Iranian form of this subscale, has been significant relation (concurrent validity) with Holms-Rahe stress questionnaire (r: 0.49) [29]. 


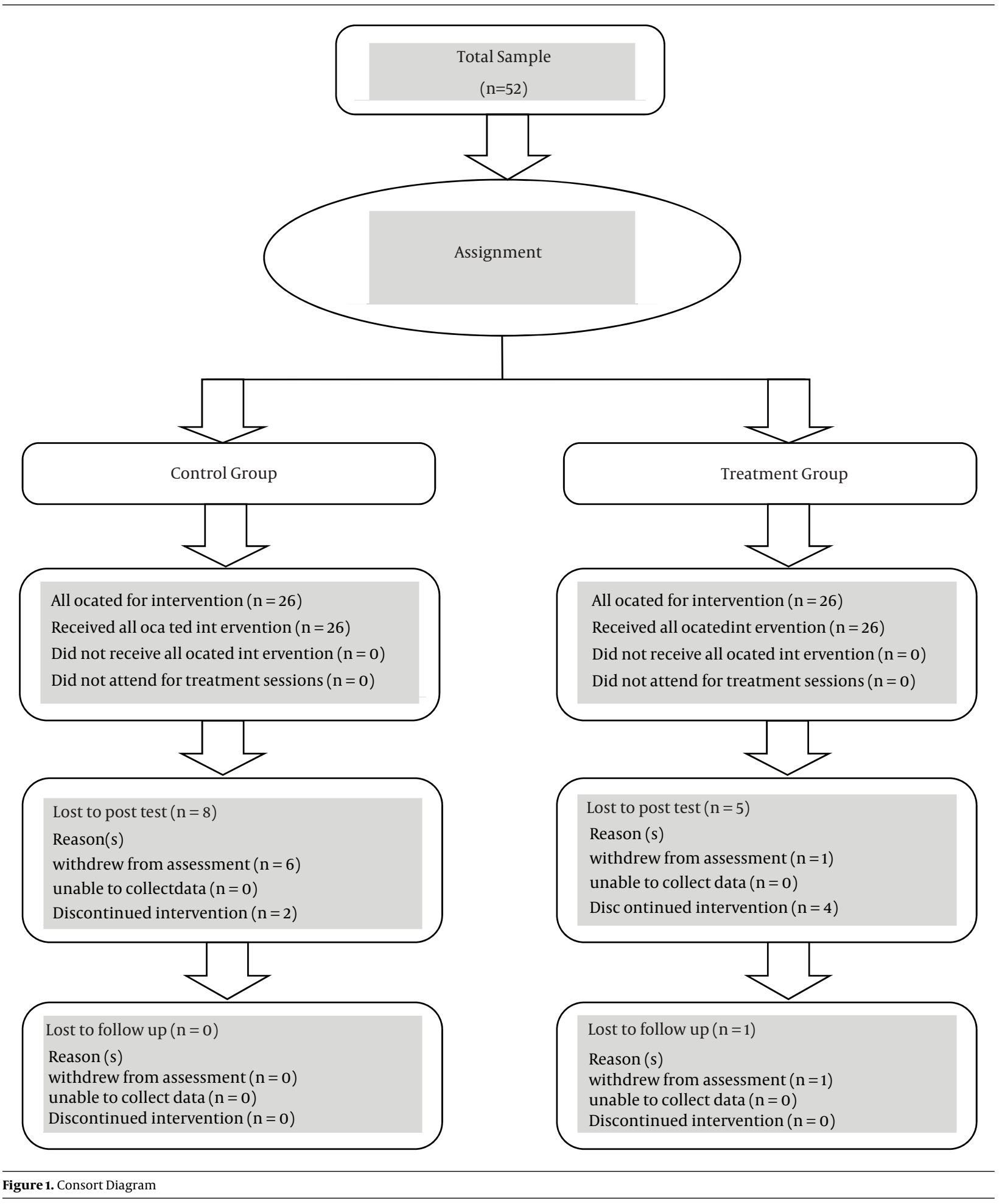

Coping strategies questionnaire: This questionnaire was published by Andler and Parker in 1990.This instrument conclude 3 subscales: problem-oriented, emotion- oriented strategies and aversion-oriented strategies. This questionnaire consist 48 questions that are completed in a likert range (1-5). Range of scores for each subscale is 
16-80.Retest reliability of these subscales has been 0.6, 0.61 and 0.64.Internal reliability has been reported higher than $0.7[30]$.

Resilience questionnaire: This questionnaire was published by Connor and Davidson in 2003. This instrument consists 25 questions that are completed in a likert range (0 - 4) [31]. In Iranian form, Internal reliability has been reported 0/89 and construct of this questionnaire has been confirmed in factor analysis [32].

Mind-body Attribution Questionnaire in Irritable Bowel Syndrome: This questionnaire was published by Gerson. This instrument concludes 2 subscales: psychological attitude (10 items), physical attitude (10 items).Internal reliability of psychological attitude and physical attitude has been reported higher than 0.76 and 0.78 [33].

Revised form of symptoms check-list (SCL-90-R): This questionnaire is constructed by Derogatis in 1994. This instrument evaluated 3 global indexes and 9 Symptoms [34]. In this research has been used of GSI index to control global psychological status.

\subsection{Data Analysis}

Data of research were analyzed with SPSS.20.In description of data, was used of mean and standard deviation. In inferential statistics-after study of presumptions and covariate variables- multivariate analysis of variances was used (MANOVA). Scores of GSI index, mind-body attribution and other control variables had not significant correlation with pretest scores, so we did not need to control them.

\section{Results}

The descriptive findings (means and standard deviations) of variables are shown in Table 1 and inferential statistics shown in Table 2.

In terms of results of Table 2, there is a significant difference in follow-up scores of stress and posttest and posttest scores of emotion-oriented strategies between two groups. There was not observed significant differences in other variables. To determine of exalter effect size of DBT on variables, was used of Cohen index. In terms of d Cohen, effect sizes that are less of 0.5 are low, between of 0.2 - 0.5 are moderate and more than 0.5 are high. As shown in Table 2, size of effects of stress scores of follow-up and emotion-focused strategies scores of post-test are more than 0.5.

\section{Discussion}

This study aimed to determine the efficacy of dialectical behavioral therapy on stress, resilience, and coping strategies of IBS patients.

In study of stress results, mean scores decreased in the posttest, but increased remarkably in the follow-up, i.e. the reversal effect of intervention. One cause that likely could explain this finding is that in Iran, economical and family stressors are prevalent and unexpected which would have been influential on the stress level of some participants. In literature, there is no interventional research in DBT on irritable bowel syndrome. However, a research, examining mindfulness (as an important stage of DBT) in IBS [35], showed significant difference in psychological symptoms in post-test and follow-up stages.

An important variable that currently is studied in psychological researches is resilience. Some economic and social factors could not be removed from participants' lives such as low income of family, marital infidelity, that were the cases of some participants; it is recommended to increase the level of resilience in these patients. In dialectical behavior therapy (especially in mindfulness and distress tolerance), it could be focused on acceptance of these problems and maintain motivation and hope. Particularly, the underlying philosophy of DBT is Zen custom (emphasized on acceptance of life realities). Although no significant difference was observed, the increase of resilience in DBT group was more than the control group.

In studying the results of coping strategies, a similar trend is observed in problem-oriented and emotionoriented coping strategies. Of course, the remission and effect size of emotion-oriented strategies are more than problem-oriented strategies. It seems that patients prefer primarily decrease in emotional coping strategies (such as caffeine drinks, over eating, and watching TV), and then utilizing problem-oriented strategies (such as problemsolving and planning); it is likely because of higher simplicity of emotional strategies. Another important point is supportive network. It seems that the questions of coping strategies questionnaire [24] in relation to supportive network are in relation to both emotional and problem coping strategies, which could be confusing. Regarding avoidant coping strategies, remission has been low. Generally, psychometric properties of these subscales are poor compared to emotion and problem strategies. It has lower internal consistency and convergent validity.

In this study, due to time constraints, there is not possible to pairing two groups based on clinical characteristics (such as predominant symptoms, the disease duration and related diseases) and demographic characteristics (such as gender, economic and marital status). It is suggested that the mentioned issues will be considered in order to increase generalization of the results. Also, because of symptoms such as abdominal pain, diarrhea and flatulence, the specialized doctor had to prescribe the drug inevitably and 
Table 1. Descriptive Statistics of Participants

\begin{tabular}{|c|c|c|c|}
\hline \multirow[t]{2}{*}{ Variables } & \multicolumn{3}{|c|}{ Indexes } \\
\hline & Pre-Test $($ Mean $\pm S D)$ & Post-Test $($ Mean \pm SD) & Follow-Up $($ Mean $\pm S D)$ \\
\hline \multicolumn{4}{|l|}{ Stress } \\
\hline DBT & $13.45 \pm 6.61$ & $11.75 \pm 5.93$ & $13.35 \pm 5.62$ \\
\hline Control & $14.11 \pm 4.05$ & $13 \pm 4.51$ & $12.11 \pm 5.58$ \\
\hline \multicolumn{4}{|l|}{ Resiliency } \\
\hline DBT & $57.05 \pm 16.65$ & $65.25 \pm 10.67$ & $15.17 \pm 60.6$ \\
\hline Control & $48.27 \pm 17.59$ & $51.16 \pm 17.49$ & $48.88 \pm 18.10$ \\
\hline \multicolumn{4}{|c|}{ Problem-oriented strategies } \\
\hline DBT & $56.4 \pm 9.96$ & $57.6 \pm 7.611$ & $59.2 \pm 8.25$ \\
\hline Control & $50.88 \pm 10.96$ & $50.833 \pm 9.394$ & $51 \pm 10.20$ \\
\hline \multicolumn{4}{|c|}{ Emotion -oriented strategies } \\
\hline DBT & $50.05 \pm 12.77$ & $44.85 \pm 9.60$ & $49.45 \pm 12.42$ \\
\hline Control & $49.66 \pm 9.97$ & $48.88 \pm 8.91$ & $48.66 \pm 8.61$ \\
\hline \multicolumn{4}{|c|}{ Aversive-oriented strategies } \\
\hline DBT & $42.65 \pm 11.32$ & $42.95 \pm 5.75$ & $43.7 \pm 5.63$ \\
\hline Control & $39.61 \pm 7.03$ & $40 \pm 7.78$ & $40.61 \pm 7.28$ \\
\hline
\end{tabular}

Table 2. Results of Multiple Analyses of Co Variances

\begin{tabular}{|c|c|c|c|}
\hline \multirow[t]{2}{*}{ Variables } & \multicolumn{3}{|c|}{ Indexes } \\
\hline & $\mathbf{F}$ & PValue & Cohen Index \\
\hline \multicolumn{4}{|l|}{ Stress } \\
\hline Post-test & 0.623 & 0.435 & 0.25 \\
\hline Follow-up & 3.5 & 0.07 & 0.6 \\
\hline \multicolumn{4}{|l|}{ Resiliency } \\
\hline Post-test & 2.628 & 0.114 & 0.27 \\
\hline Follow-up & 0.794 & 0.379 & 0.28 \\
\hline \multicolumn{4}{|c|}{ Problem-oriented strategies } \\
\hline Post-test & 0.394 & 0.534 & 0.2 \\
\hline Follow-up & 1.514 & 0.227 & 0.39 \\
\hline \multicolumn{4}{|c|}{ Emotion -oriented strategies } \\
\hline Post-test & 6.275 & 0.017 & 0.8 \\
\hline Follow-up & 0.634 & 0.431 & 0.25 \\
\hline \multicolumn{4}{|c|}{ Aversive-oriented strategies } \\
\hline Post-test & 0.001 & 0.974 & 0.01 \\
\hline Follow-up & 0.000 & 0.986 & 0 \\
\hline
\end{tabular}

there was not possible to choose the pure groups. In order to increase the statistical power and generalize the results, it will be suggested that, in future researches, there will be selected larger sample size and there will be performed the follow-up stages.

Dialectical behavior therapy could be a helpful intervention in IBS patients. To increase the effect size of this method, it needs longer intervention, and better con- 
ducted individually. However, these results could be hopeful in considering economic problems in the society of Iran.

\section{Acknowledgments}

This study was related to $\mathrm{PhD}$ thesis and supported by ministry of science, research and technology, Iran (with number code 2091888). We also thank also the personnel of Psycho-somatic research center of Isfahan university of medical sciences for helping to sample selection.

\section{Footnotes}

Authors' Contribution: Sayed Abbas Haghayegh designed research, analyzed data and wrote paper; Hamid Taher Neshatdoost as supervisor of research process; Peiman Adibi conducted sampling; Farah Shafii conducted intervention.

\section{Conflict of Interest: No conflict of interests.}

Funding/Support: Ministry of science, research and technology.

\section{References}

1. Lovell RM, Ford AC. Global prevalence of and risk factors for irritable bowel syndrome: a meta-analysis. Clin Gastroenterol Hepatol. 2012;10(7):712-721 e4. doi: 10.1016/j.cgh.2012.02.029. [PubMed: 22426087].

2. Longstreth GF, Thompson WG, Chey WD, Houghton LA, Mearin F, Spiller RC. Functional bowel disorders. Gastroenterology. 2006;130(5):1480-91. doi: 10.1053/j.gastro.2005.11.061. [PubMed: 16678561].

3. Drossman DA, Morris CB, Schneck S, Hu YJ, Norton NJ, Norton WF, et al. International survey of patients with IBS: symptom features and their severity, health status, treatments, and risk taking to achieve clinical benefit. J Clin Gastroenterol. 2009;43(6):541-50. doi: 10.1097/MCG.0b013e318189a7f9. [PubMed: 19384249].

4. Thompson JJ, Elsenbruch S, Harnish MJ, Orr WC. Autonomic functioning during REM sleep differentiates IBS symptom subgroups. Am J Gastroenterol. 2002;97(12):3147-53. doi: 10.1111/j.1572-0241.2002.07112.x. [PubMed: 12492202].

5. Lackner JM. No brain, no gain: The role of cognitive processes in irritable bowel syndrome. J Cogn Psychother. 2005;19(2):125-36. doi: 10.1891/jcop.19.2.125.66788.

6. Kumano H, Kaiya H, Yoshiuchi K, Yamanaka G, Sasaki T, Kuboki T. Comorbidity of irritable bowel syndrome, panic disorder, and agoraphobia in a Japanese representative sample. Am J Gastroenterol. 2004;99(2):370-6. [PubMed: 15046231].

7. Blanchard EB, Schaff L. Psychosocial aspects of assessment and treatment of irritable bowel syndrome in adults and recurrent abdominal pain in children. Journal of Consulting and Clinical Psychology. 2002;70:725-38.

8. Wenzel A, Haugen EN, Jackson LC, Brendle JR. Anxiety symptoms and disorders at eight weeks postpartum. J Anxiety Disord. 2005;19(3):295311. doi: 10.1016/j.janxdis.2004.04.001. [PubMed: 15686858].

9. Folks DG. The interface of psychiatry and irritable bowel syndrome. Curr Psychiatry Rep. 2004;6(3):210-5. [PubMed: 15142474].
10. Werner EE. Journeys from childhood to midlife: risk, resilience, and recovery. Pediatrics. 2004;114(2):492. [PubMed: 15286237].

11. Cuomo C, Sarchiapone M, Giannantonio MD, Mancini M, Roy A. Aggression, impulsivity, personality traits, and childhood trauma of prisoners with substance abuse and addiction. Am J Drug Alcohol Abuse. 2008;34(3):339-45. doi: 10.1080/00952990802010884. [PubMed: 18428076].

12. Paulhan I, Nuissier J, Quintard B, Cousson F, Bourgeois M. [The measurement of "coping". French translation and validation of the Vitaliano's scale (Vitaliano et al. 1985)]. Ann Med Psychol (Paris). 1994;152(5):292-9. [PubMed: 7944097].

13. Kearney DJ, Brown-Chang J. Complementary and alternative medicine for IBS in adults: mind-body interventions. Nat Clin Pract Gastroenterol Hepatol. 2008;5(11):624-36. doi: 10.1038/ncpgasthep1257. [PubMed: 18825145].

14. Stanculete M, Pojoga C, Dumitrascu DL. Relationship among healthrelated quality of life, coping strategies and dysfunctional beliefs in irritable bowel syndrome. J Psychosom Res. 2015;78(6):625. doi: 10.1016/j.jpsychores.2015.03.123.

15. Lea R, Whorwell PJ. Quality of life in irritable bowel syndrome. Phar macoeconomics. 2001;19(6):643-53. [PubMed: 11456212].

16. Owang G. Illness Perception in people with acute bacterial gastroenteritis.J Health Psychol. 2003;8:694-704.

17. Telch CF, Agras WS, Linehan MM. Dialectical behavior therapy for binge eating disorder. J Consult Clin Psychol. 2001;69(6):1061-5. [PubMed: 11777110].

18. Linehan MM, Dimeff LA, Reynolds SK, Comtois KA, Welch SS, Heagerty $P$, et al. Dialectical behavior therapy versus comprehensive validation therapy plus 12-step for the treatment of opioid dependent women meeting criteria for borderline personality disorder. Drug Alcohol Depend. 2002;67(1):13-26. [PubMed: 12062776].

19. Hesslinger B, Tebartz van Elst L, Nyberg E, Dykierek P, Richter H, Berner $\mathrm{M}$, et al. Psychotherapy of attention deficit hyperactivity disorder in adults-a pilot study using a structured skills training program. Eur Arch Psychiatry Clin Neurosci. 2002;252(4):177-84. doi: 10.1007/s00406002-0379-0. [PubMed: 12242579].

20. Lynch TR, Morse JQ, Mendelson T, Robins CJ. Dialectical behavior therapy for depressed older adults: a randomized pilot study. Am J Geriatr Psychiatry. 2003;11(1):33-45. [PubMed: 12527538].

21. Dykstra EJ. Dialectical behavior therapy. A new direction in psychotherapy. Intercept Center, Aurora Mental Health Center University of Denver; 2003.

22. Mc Cann R, Ball EM, Ivanoff A. The effectiveness of dialectical behavior therapy in reducing burnout among forensic inpatients.. Cognitive Behav Practice. 2000;7:447-56.

23. Lynch TR, Chapman AL, Rosenthal MZ, Kuo JR, Linehan MM. Mechanisms of change in dialectical behavior therapy: theoretical and empirical observations. J Clin Psychol. 2006;62(4):459-80. doi 10.1002/jclp.20243. [PubMed: 16470714].

24. Wagner AW, Rizvi SL, Harned MS. Applications of dialectical behavior therapy to the treatment of complex trauma-related problems: when one case formulation does not fit all. J Trauma Stress. 2007;20(4):391400. doi: 10.1002/jts.20268. [PubMed: 17721961].

25. Witthoft M, Borgmann E, White A, Dyer A. Body-related attentional biases in patients with posttraumatic stress disorder resulting from childhood sexual abuse with and without co-occurring borderline personality disorder. J Behav Ther Exp Psychiatry. 2015;46:72-7. doi: 10.1016/j.jbtep.2014.07.010. [PubMed: 25244677].

26. Blanchard EB. Irritable bowel syndrome. Washington, DC: American Psychological Association; 2001.

27. Olatunji BO, Tolin DF, Lohr JM. Irritable bowel syndrome: Associated features and the efficacy of psychosocial treatments. Applied Preventive Psychol. 2004;11:125-40.

28. Mooshine C. Dialectical behavior therapy (Clinician $s$ guide). New York: Premier Publishing \& Media; 2008 
29. Sahebi A, Asghari M, Salari R. Validation of scale of depression,anxiety,stress for Iranian population. J Iran Psychol. 2006;4:299312.

30. Shokri O, Moradi AR, Farzad V, Sangari AA, Ghanai Z, Rezai A. Role of personality traits and coping strategies on mental health of students. Iran J Adv Cogn Sci. 2004;1:28-38.

31. Connor KM, Davidson JR. Development of a new resilience scale the Connor-Davidson Resilience Scale (CD-RISC). Depress Anxiety. 2003;18(2):76-82. doi: 10.1002/da.10113. [PubMed: 12964174].

32. Fadardi JS, Azad H, Nemati A. The relationship between resilience, motivational structure, and substance use. Procedia Social Behav Sci. 2010;5:1956-60. doi: 10.1016/j.sbspro.2010.07.395.
33. Gerson MJ, Gerson CD, Awad RA, Dancey C, Poitras P, Porcelli P, et al. An international study of irritable bowel syndrome: family relationships and mind-body attributions. Soc Sci Med. 2006;62(11):2838-47. doi: 10.1016/j.socscimed.2005.10.019. [PubMed: 16337723].

34. Groth-Marnat G, Baker S. Digit Span as a measure of everyday attention: a study of ecological validity. Percept Mot Skills. 2003;97(3 Pt 2):1209-18. doi: 10.2466/pms.2003.97.3f.1209. [PubMed: 15002866].

35. Gaylord SA, Whitehead WE, Coble RS, Faurot KR, Palsson OS, Garland EL, et al. Mindfulness for irritable bowel syndrome: protocol development for a controlled clinical trial. BMC Complement Altern Med. 2009;9:24. doi: 10.1186/1472-6882-9-24. [PubMed: 19638214]. 